\title{
Lipid Profile Determination by Direct Infusion ESI-MS and Fatty Acid Composition by GC-FID in Human Milk Pools by Folch and Creamatocrit Methods
}

\author{
Adriela A. Rydlewski, ${ }^{\oplus a}$ Patrícia D. Silva, ${ }^{b}$ Luciana P. Manin, ${ }^{a}$ Christyna B. G. Tavares, ${ }^{c}$ \\ Meliana G. Paula, ${ }^{c}$ Ingrid L. Figueiredo, ${ }^{\circledR b}$ Vanessa B. M. J. C. Neia, ${ }^{a}$ Oscar O. Santos ${ }^{b}$ \\ and Jesuí $V$. Visentainer*,a,b \\ ${ }^{a}$ Programa de Pós-Graduação em Ciência de Alimentos, Universidade Estadual de Maringá (UEM), \\ 87020-900 Maringá-PR, Brazil \\ ${ }^{b}$ Hospital Universitário de Maringá (HUM), Universidade Estadual de Maringá (UEM), \\ 87083-240 Maringá-PR, Brazil \\ 'Departamento de Química, Universidade Estadual de Maringá (UEM), \\ 87020-900 Maringá-PR, Brazil
}

\begin{abstract}
Human milk (HM) is extremely important to the baby, containing a varied and balanced range of nutrients fundamental to the ideal development of the newborn. Among these nutrients, HM lipids provide $40-60 \%$ of the energy. In HM banks, the creamatocrit method is employed as a quick and solvent-free tool, however, since Folch methodology is considered reference for lipid extraction, this study compared the fatty acid (FA) composition and the lipid profile by gas chromatography with flame ionization detector (GC-FID) and direct infusion by electrospray ionization mass spectrometry (DI-ESI-MS) in pools of different HM phases, obtained from Folch and creamatocrit methods, in order to elucidate which method provides better information about HM lipids. Lipid compositon results by Folch were superior to the results obtained by creamatocrit in HM pools investigated. It means, the lipid profiles of all HM pools were more intense, and the number of FA identified by Folch was also higher in comparison to the creamatocrit method ( 21 and 6 FAs, respectively). GC-FID analysis in combination with principal component analysis (PCA) divided the methods, confirming a greater contribution of the Folch method. Therefore, Folch methodology revealed an effective lipid extraction in comparison to creamatocrit method.
\end{abstract}

Keywords: human milk pool, lipid profile, fatty acids, gas chromatography, mass spectrometry

\section{Introduction}

Human milk (HM) is considered the gold standard food to assemble the baby requirements due to the varied and balanced range of nutrients, as well as several components dispersed in the colloid liquid, which are fundamental to the ideal development of the newborn. ${ }^{1,2}$ Until the $7^{\text {th }}$ day after delivery the HM is considered colostrum, between the $8^{\text {th }}$ and $14^{\text {th }}$ day postpartum it is considered transitional milk and after the $15^{\text {th }}$ day postpartum, it is considered mature milk. ${ }^{3}$

HM lipids are extremely important for the newborn proper growth, providing $40-60 \%$ of the required energy. These lipids are composed of $98 \%$ triacylglycerols (TAGs); fatty acids (FAs) sources. ${ }^{4}$ TAGs are present in HM in the

*e-mail: jesuiv@gmail.com fat globules form, with a phospholipid structural layer providing stability. ${ }^{5,6}$

HM FAs can be monounsaturated (MUFA), polyunsaturated (PUFA) or saturated (SFA). ${ }^{4}$ SFA such as palmitic acid (PA, 16:0) and MUFA such as oleic acid (OA, 18:1n-9) present important role promoting the efficient absorption of fat and calcium by the neonate's small intestine. ${ }^{7,8}$ PUFAs such as linoleic acid (LA, 18:2n-6) and $\alpha$-linolenic acid (ALA, 18:3n-3) are precursors of long-chain polyunsaturated fatty acids (LCPUFAs) of the omega-6 family, such as arachidonic acid (Aa, 20:4n-6) and of the omega-3 family, such as eicosapentaenoic acid (Epa, 20:5n-3) and docosahexaenoic acid (Dha, 22:6n-3). These LCPUFAs have been related to increase intelligence quotient (IQ), as well as the development of the visual, nervous and cognitive systems of the child. ${ }^{1,4,9}$ Therefore, measuring the lipid profile and the fat content 
in HM requires a method that considers variations in these compounds, since it can influence the results. ${ }^{10}$

The reference method used to measure the lipid content by liquid-liquid extraction can also be employed to evaluate the lipid content of HM samples. ${ }^{10,11}$ In human milk banks (HMB), the creamatocrit method is employed as a fast and solvent-free tool, which applies simply centrifugation to measure the fat content of HM after separation of the cream layer. ${ }^{12,13}$ To analyze lipids composition in HM, the use of gas chromatography (GC) is generally employed, providing satisfactory results, although it is not conclusive. ${ }^{14}$ Thereby, complementary analyses, such as mass spectrometric is required, in order to elucidate the sample total lipid profile. ${ }^{15}$

Folch methodology is considered reference for lipid extraction, so this study compared the fat content and the FA composition by gas chromatography with flame ionization detection (GC-FID), and the lipid profiles by direct infusion by electrospray ionization mass spectrometry (DI-ESI-MS) in colostrum, transitional and mature HM pool samples, obtained from Folch and creamatocrit methods, in order to elucidate which method provides better information about the HM lipids.

\section{Experimental}

\section{Samples of pooled HM}

In order to carry out the present study, it was necessary to request authorization from the Commission for the Regulation of Academic Activities (COREA) of the University Hospital of Maringá (HUM; number 1926), as well as insertion in the Brazil Platform and approval by the Research Ethics Committee (CEP; number 2,230,946). Samples of pasteurized human milk were obtained from the HMB located at HUM (Maringá, Paraná), from September to October 2017. All HM samples were collected at refrigeration temperature $\left(4^{\circ} \mathrm{C}\right)$, transported in a thermal container with frozen thermogel and coupled digital thermometer for temperature control. Donors were selected at a specific milk phase, being colostrum, transitional or mature. $100 \mathrm{~mL}$ of each milk phase were pooled completing a total volume of $300 \mathrm{~mL}$ in each pool. As inclusion criteria, HM samples were obtained from donors with a mean gestational age of 39 weeks and age between 25 and 35 years.

\section{Lipid extraction of human milk pools}

HM lipids were extracted by Folch et al. ${ }^{11}$ and by creamatocrit methodologies, according to Lucas et al. ${ }^{12}$

\section{Folch method}

For the analysis by Folch method, $10 \mathrm{~mL}$ of $\mathrm{HM}$ samples from each pool (colostrum, transitional and mature) in triplicate were used to obtain $125 \mathrm{mg}$ of lipids for esterification/transesterification and subsequent identification of fatty acids methyl esters (FAMEs) by GC-FID and analysis of the lipid profile by DI-ESI-MS.

\section{Creamatocrit method}

For lipid extraction by creamatocrit method, $1 \mathrm{~mL}$ from each HM pool were homogenized, placed on a polyvinyl chloride (PVC) coated shelf and heated in water bath at $40{ }^{\circ} \mathrm{C}$ for $10 \mathrm{~min}$. Three aliquots of $75 \mu \mathrm{L}$ of each HM samples were collected using capillary tubes with outer/inner diameter of $1.5 / 1.0 \mathrm{~mm}$, respectively (microhematocrit tubes, Perfecta ${ }^{\circledR}$, São Paulo, Brazil); one end was sealed with Bunsen's burner. The tubes were centrifuged in a microhematocrit centrifuge (Excelsa ${ }^{\circledR}$ Flex 3400, Fanem, Brazil) at $4000 \mathrm{rpm}$ for $15 \mathrm{~min}$. The cream content was calculated using the following calculation according to Lucas et al.: ${ }^{12}$

Cream Column $(\mathrm{mm}) \times 100 /$ Total Column $(\mathrm{mm})=$ Cream (\%)

The fat content was calculated using the following calculation:

$($ Cream $(\%)-0.59) / 1.46=$ Lipids $(\%)$

Each creamatocrit microtube generated $2 \mathrm{mg}$ of lipids. Subsequently, 63 microtubes of each HM pool were used to obtain $125 \mathrm{mg}$ of lipids, which were esterified/ transesterified, FAMEs identified by GC-FID and lipid profile analyzed by DI-ESI-MS.

\section{Lipid esterification/transesterification}

FAMEs were prepared according to Hartman and Lago; ${ }^{16}$ approximately $50.0 \mathrm{mg}$ of sample was weighed in a tube, $4.0 \mathrm{~mL}$ of sodium hydroxide solution $(\mathrm{NaOH})$ was added in $0.5 \mathrm{~mol} \mathrm{~L}^{-1}$ methanol. The tubes were heated in a boiling water bath for $5 \mathrm{~min} .5 .0 \mathrm{~mL}$ of esterification reagent (prepared from a mixture of ammonium chloride $(16.0 \mathrm{~g})$, sulfuric acid $(24.0 \mathrm{~mL})$ and methanol $(480.0 \mathrm{~mL}))$ was added. The tubes were heated again in a boiling water bath for $5 \mathrm{~min}$. Then, $4.0 \mathrm{~mL}$ of saturated sodium chloride solution $(\mathrm{NaCl})$ and $2.0 \mathrm{~mL}$ of hexane were added. The tubes were agitated vigorously for $30 \mathrm{~s}$. The solution was placed in the refrigerator for $24 \mathrm{~h}$, and then the supernatant, which is composed of FAMEs, was collected. 
Gas chromatography with flame ionization detector analysis (GC-FID)

FAMEs were analyzed according to Simionato et al. ${ }^{17}$ using a Thermo Scientific Trace Ultra 3300 gas chromatograph (MA, USA), equipped with flame ionization detector (FID), fused silica capillary column (CP-7420 Select FAME, $100 \mathrm{~m}$ size $\times 0.25 \mathrm{~mm}$ internal diameter and $0.25 \mu \mathrm{m}$ cyanopropyl thin film as the stationary phase) and a split/splitless injector. The gas fluxes were: $1.4 \mathrm{~mL} \mathrm{~min}^{-1}$ for the make up gas $\left(\mathrm{H}_{2}\right), 30 \mathrm{~mL} \mathrm{~min}^{-1}$ for the carrier gas $\left(\mathrm{N}_{2}\right), 30$ and $300 \mathrm{~mL} \mathrm{m^{-1 }}$ for the flame gas $\left(\mathrm{H}_{2}\right)$ and synthetic air, respectively. A sample volume of $2 \mu \mathrm{L}$ was injected in triplicate with split mode of 1:100. The injector and detector temperatures were $235{ }^{\circ} \mathrm{C}$. The column temperature was raised to $65^{\circ} \mathrm{C}$ for $4 \mathrm{~min}$, followed by a $16{ }^{\circ} \mathrm{C} \mathrm{min}{ }^{-1}$ heating ramp to $185{ }^{\circ} \mathrm{C}$, which was held for $12 \mathrm{~min}$. Thereafter, a new ramp of $20^{\circ} \mathrm{C} \mathrm{min}^{-1}$ was applied up to $235^{\circ} \mathrm{C}$ and maintained for $14 \mathrm{~min}$, totaling an analysis time of $40 \mathrm{~min}$. For FAME identification, retention times were compared with relative analytical standards (FAME Mix, C4-C24, Sigma-Aldrich, Darmstadt, Germany). For quantification, theoretical FID correction factor values were used in the calculations to obtain FA concentration $\left(\mathrm{mg} \mathrm{g}^{-1}\right)$. The theoretical FID correction is required due to the signal magnitude generated by the detector which is proportional to the carbon and hydrogen atoms in the molecule analyzed. Besides that, for quantification, $1 \mathrm{mg} \mathrm{mL}^{-1}$ of internal standard tricosanoic acid methyl ester (23:0, Sigma-Aldrich, Darmstadt, Germany), in isooctane, was used, as described by Visentainer. ${ }^{18}$ ChromQuest $^{\mathrm{TM}} 5.0$ software was used to determine the retention times and peak areas of FAMEs.

Sample preparation of HM pools using DI-ESI(+)-MS and instrumental conditions

Lipid profile of the HM pools in different phases was evaluated embracing the mass/charge $(\mathrm{m} / \mathrm{z})$ ranging from 100 to 1200 , in triplicate. For this, $50.0 \mathrm{mg}$ of lipid from each HM pool extracted by Folch and creamatocrit methods and prepared according to Youzbachi et al..$^{19}$ with modifications, were diluted in $950.0 \mu \mathrm{L}$ of chloroform (Synth, São Paulo, Brazil). Subsequently, $5.0 \mu \mathrm{L}$ of this solution was diluted with the addition of $1.0 \mathrm{~mL}$ of methanol/chloroform 9:1 (high-performance liquid chromatography (HPLC) grade, J.T.Baker ${ }^{\circledR}$, Radnor, USA). Therefore, $20.0 \mu \mathrm{L}$ of ammonium formate $0.10 \mathrm{~mol} \mathrm{~L}^{-1}$, prepared in methanol (97\%, Sigma-Aldrich, Darmstadt, Germany) was added to the samples in order to form adducts and consequently favor ionization via $\left[\mathrm{TAG}+\mathrm{NH}_{4}\right]^{+}$, without affecting the reproducibility of the MS lipid profile.

A triple quadrupole mass spectrometer (XEVO TQ-D, Waters, Massachusetts, USA) was used with a source of electrospray ionization (ESI). Properly prepared HM pool samples were introduced into the system by direct infusion, being ionized by electrospray operating in positive ion mode (ESI(+)) according to the following conditions: source temperature $\left(150{ }^{\circ} \mathrm{C}\right)$, desolvation temperature $\left(200{ }^{\circ} \mathrm{C}\right)$, capillary voltage $(3.00 \mathrm{kV})$, cone voltage $(20.00 \mathrm{~V})$ and desolvation gas flow $\left(500 \mathrm{~L} \mathrm{~h}^{-1}\right)$. Data were processed using MassLynx ${ }^{\mathrm{TM}}$ software.

\section{Statistical analysis}

FA composition obtained by GC-FID were submitted to analysis of variance (ANOVA) and $t$-tests; means were compared by Tukey's test with a 95\% significance level. Results obtained by GC-FID were performed to principal component analysis (PCA) using RStudio software. ${ }^{20}$

\section{Results and Discussion}

\section{Fat content in HM pools}

Table 1 demonstrates that the total lipids (TL) percentage results presented significant differences among the same pools in all HM phases evaluated by both methods, confirming the greater efficiency of the Folch lipid extraction method.

Comparing the results of the TL percentage between the different phases of HM pools extracted using the same

Table 1. Total lipids in different phases of human milk pools assessed by the Folch and creamatocrit methods

\begin{tabular}{lccc}
\hline \multirow{2}{*}{ Method } & \multicolumn{3}{c}{ Total lipids in human milk pools $/ \%$} \\
\cline { 2 - 4 } & $\mathrm{C}$ & $\mathrm{T}$ & $\mathrm{M}$ \\
\hline Folch & $2.88^{\mathrm{Ab}} \pm 0.05$ & $3.97^{\mathrm{aA}} \pm 0.31$ & $3.08^{\mathrm{aB}} \pm 0.73$ \\
Creamatocrit & $2.32^{\mathrm{bB}} \pm 0.03$ & $3.09^{\mathrm{bA}} \pm 0.10$ & $2.13^{\mathrm{bB}} \pm 0.58$ \\
\hline
\end{tabular}

aResults expressed as mean \pm standard deviation of three replicates. Equivalent phases of human milk were compared using both methods. Means followed by different lowercase letters $(\mathrm{a}$ and $\mathrm{b})$ in the same column are significantly different by $t$-test $(p<0.05)$. Different phases in the same method were also compared. Means followed by different uppercase letters (A and B) on the same line are significantly different by Tukey's test $(p<0.05)$. C: colostrum; T: transitional; M: mature. 
method, it was possible to observe that the transitional milk pool presented higher lipid content in comparison to the other pools. Several factors can influence the HM lipid content, such as: time of day, maternal diet, gestational age at the time of the baby's birth, and feeding of the lactating. ${ }^{\text {? }}$

A study by O'Neill et al. ${ }^{21}$ compared the creamatocrit method with mid-infrared spectroscopy; it was concluded that creamatocrit can overestimate the HM fat content due to the sample centrifugation that can lead to less compression of the creamy layer, generating higher values for the calculated fat content. If this factor is considered, the results obtained by the creamatocrit method may be even inferior, since the FA values in $\mathrm{mg} \mathrm{g}^{-1}$ obtained by GC-FID were approximately ten times lower than the results obtained by Folch methodology.

\section{Fatty acid composition by GC-FID}

According to Simionato et al.,${ }^{17}$ the FA quantification should be performed using internal standards due to its reliability and also to facilitate the results interpretation obtained by GC, allowing to express the results in mass. Therefore, it is possible to express the results as FA mass instead of FAME mass, through the conversion factors. ${ }^{22}$ Consequently, in this work, the internal standard (23:0) was injected with samples to minimize method errors.

A total of 21 FAs were identified and quantified by GC in the different pools obtained after TL extraction by Folch and six FAs by creamatocrit method. All results obtained by the Folch method were higher in mg concentration and in quantity of FA identified in comparison to the creamatocrit method (Table 2).

The transitional milk pool, in which TL extraction was performed by the Folch method, presented the highest level of SFA sum ( $\Sigma$ SFA) $\left(194.01 \pm 0.04 \mathrm{mg} \mathrm{g}^{-1}\right)$, representing $56.47 \%$ of the TL. Colostrum samples presented $152.47 \pm 1.08 \mathrm{mg} \mathrm{g}^{-1}(51.68 \%)$ and mature milk pools contained $104.19 \pm 5.43 \mathrm{mg} \mathrm{g}^{-1}(44.74 \%)$. By the creamatocrit method, the pool presenting the highest $\Sigma$ SFA was the mature milk pool $\left(12.85 \pm 0.72 \mathrm{mg} \mathrm{g}^{-1}\right)$, representing $57.67 \%$ of the $\mathrm{TL}$, followed by the transitional milk $\left(12.13 \pm 0.42 \mathrm{mg} \mathrm{g}^{-1}\right)$ and colostrum pools $\left(10.43 \pm 0.43 \mathrm{mg} \mathrm{g}^{-1}\right)$, accounting for 57.43 and $50.24 \%$ of the $\mathrm{TL}$ in it, respectively.

Palmitic acid (P, 16:0) was the major contributor among the SFA discovered in all HM pools, by both methods. It is extremely positive since PA contributes to the absorption of fats and minerals. Moreover, PA is related to reduced crying behavior in infants because it influences levels of anandamide, which has analgesic effects. ${ }^{23,24}$
By the Folch method, the colostrum pool presented the highest value of MUFA sum ( MUFA): $126.39 \pm 0.90 \mathrm{mg} \mathrm{g}^{-1}$, representing $42.84 \%$ of the TL. The main MUFA discovered in these samples was oleic acid (O, 18:1n-9), presenting a value of $126.04 \pm 0.94 \mathrm{mg} \mathrm{g}^{-1}$. $O$ revealed a significant difference between the other pools extracted by the same method and by the creamatocrit method in the same colostrum pool $\left(7.07 \pm 0.14 \mathrm{mg} \mathrm{g}^{-1}\right)$. In a study by Moltó-Puigmartí et al..$^{25}$ comparing MUFA concentrations during the three lactation phases, a reduction in these FAs with the progression of the lactation phases was also revealed. As can be observed in Table 2, the $\mathrm{O}$ concentrations were lower in the transitional and mature milk pools by Folch methodology, which can be explained by the fact that colostrum must provide newborns greater MUFAs proportions during the first days of life, related to myelinogenesis. ${ }^{26}$

The transitional milk pool was higher in relation to PUFA sum ( PUUFA), with a result of $47.23 \pm 0.70 \mathrm{mg} \mathrm{g}^{-1}$ $(13.74 \% \mathrm{TL})$ by the Folch method, differing significantly from the creamatocrit method in the same pool $\left(2.93 \pm 0.50 \mathrm{mg} \mathrm{g}^{-1}\right)$. The omega-6 PUFA that most contributed to this sum was L (18:2n-6). The results for $\mathrm{L}$ by the creamatocrit method in the colostrum pool were higher than the others and agreed with the results obtained by Moltó-Puigmartí et al. ${ }^{25}$ who also determined FAs by the same method and found higher $\mathrm{L}$ values in colostrum in comparison to transitional and mature milk. During the first days of life, due to physiological immaturity, colostrum is essential to provide to the newborn a milk with higher L proportions, which besides being used as energy source, it is also a precursor of long-chain n-6 polyunsaturated fatty acids (LCn-6PUFAs), with important activities. ${ }^{27}$

Similar to L, $\operatorname{Ln}(18: 3 n-3)$ is also a precursor of longchain $n-3$ polyunsaturated fatty acids (LCn-3PUFAs) and it was the main contributor to the omega-3 PUFAs sum in the transition milk pool, followed by mature milk and colostrum by the Folch method.

Arachidonic acid (Aa, 20:4n-6), which is an LCn-6PUFA, differed significantly in the colostrum pool $\left(2.18 \pm 0.28 \mathrm{mg} \mathrm{g}^{-1}\right)$ in comparison to the transitional and mature pools $\left(1.70 \pm 0.11\right.$ and $1.37 \pm 0.11 \mathrm{mg} \mathrm{g}^{-1}$, respectively) by the Folch method. Aa and LCn-3PUFA such as Epa (20:5n-3) and Dha (22:6n-3) accumulate in fetal tissues mainly during the last trimester of gestation and in the first months of life, with Dha being especially abundant in the brain and related to adequate neurodevelopment. Additionally, Dha contributes to $15 \%$ of the total FAs in the human frontal cortex, a brain region that develops intensely after birth and is responsible for the ability to understand, 
Table 2. Fatty acid composition determined by GC-FID in different phases of human milk pools by the Folch and creamatocrit methods

\begin{tabular}{|c|c|c|c|c|c|c|}
\hline \multirow{3}{*}{ Fatty acid } & \multicolumn{6}{|c|}{ Human milk pools / ( $\mathrm{mg} \mathrm{g}^{-1}$ of sample) } \\
\hline & \multicolumn{3}{|c|}{ Folch } & \multicolumn{3}{|c|}{ Creamatocrit } \\
\hline & $\mathrm{C}$ & $\mathrm{T}$ & M & $\mathrm{C}$ & $\mathrm{T}$ & M \\
\hline $10: 0$ & $6.85^{\mathrm{a}} \pm 0.04$ & $6.59^{\mathrm{a}} \pm 1.28$ & $4.86^{\mathrm{a}} \pm 0.75$ & ND & ND & ND \\
\hline 12:0 & $19.93^{\mathrm{bA}} \pm 0.54$ & $25.87^{\mathrm{a}_{\mathrm{A}}} \pm 2.71$ & $12.35^{\mathrm{cA}} \pm 016$ & $1.32^{\mathrm{aB}} \pm 0.23$ & $2.01^{\mathrm{aB}} \pm 0.06$ & $1.80^{\mathrm{aB}} \pm 0.37$ \\
\hline 14:0 & $26.96^{\mathrm{bA}} \pm 0.04$ & $45.93^{\mathrm{aA}} \pm 2.86$ & $12.82^{\mathrm{cA}} \pm 0.16$ & $1.10^{\mathrm{aB}} \pm 0.08$ & $1.93^{\mathrm{aB}} \pm 0.06$ & $1.39^{\mathrm{aB}} \pm 0.37$ \\
\hline 15:0 & $0.52^{\mathrm{a}} \pm 0.10$ & $0.53^{\mathrm{a}} \pm 0.07$ & $0.38^{\mathrm{a}} \pm 0.05$ & ND & ND & ND \\
\hline $16: 0$ & $71.79^{\mathrm{a} A} \pm 0.84$ & $78.65^{\mathrm{a}_{\mathrm{A}}} \pm 4.56$ & $52.67^{\mathrm{bA}} \pm 5.68$ & $6.14^{\mathrm{aB}} \pm 0.15$ & $6.09^{\mathrm{aB}} \pm 0.45$ & $7.09^{\mathrm{aB}} \pm 0.40$ \\
\hline 16:1 & $6.821^{\mathrm{a}} \pm 0.48$ & $7.65^{\mathrm{a}} \pm 0.11$ & $6.75^{\mathrm{a}} \pm 0.61$ & ND & ND & ND \\
\hline 17:0 & $0.94^{\mathrm{b}} \pm 0.08$ & $4.17^{\mathrm{a}} \pm 0.03$ & $0.51^{\mathrm{b}} \pm 0.05$ & ND & ND & ND \\
\hline $17: 1$ & $0.49^{\mathrm{a}} \pm 0.08$ & $0.47^{\mathrm{a}} \pm 0.03$ & $0.30^{\mathrm{a}} \pm 0.02$ & ND & ND & ND \\
\hline 18:0 & $13.34^{\mathrm{bA}} \pm 0.26$ & $22.20^{\mathrm{a}_{\mathrm{A}}} \pm 0.14$ & $12.26^{\mathrm{bA}} \pm 1.82$ & $1.85^{\mathrm{aB}} \pm 0.15$ & $2.08^{\mathrm{aB}} \pm 0.18$ & $2.55^{\mathrm{aB}} \pm 0.09$ \\
\hline $18: 1 n-9$ & $126.04^{\mathrm{a}_{\mathrm{A}}} \pm 0.94$ & $102.02^{\mathrm{bA}} \pm 11.07$ & $91.45^{\mathrm{bA}} \pm 6.63$ & $7.07^{\mathrm{aB}} \pm 0.14$ & $6.05^{\mathrm{aB}} \pm 0.56$ & $7.09^{\mathrm{aB}} \pm 0.25$ \\
\hline $18: 2 n-6$ & $14.49^{\mathrm{cA}} \pm 0.73$ & $41.03^{\mathrm{a} A} \pm 0.87$ & $33.61^{\mathrm{bA}} \pm 1.51$ & $3.23^{\mathrm{aB}} \pm 0.11$ & $2.93^{\mathrm{aB}} \pm 0.20$ & $2.34^{\mathrm{aB}} \pm 0.50$ \\
\hline $18: 3 n-6$ & $0.31^{\mathrm{a}} \pm 0.01$ & $0.12^{\mathrm{b}} \pm 0.01$ & $0.30^{\mathrm{a}} \pm 0.03$ & ND & ND & ND \\
\hline $18: 3 n-3$ & $0.74^{\mathrm{c}} \pm 0.11$ & $5.57^{\mathrm{a}} \pm 0.37$ & $3.34^{\mathrm{b}} \pm 0.22$ & ND & ND & ND \\
\hline 20:0 & $1.74^{\mathrm{a}} \pm 0.16$ & $0.58^{\mathrm{b}} \pm 0.05$ & $0.913^{\mathrm{b}} \pm 0.18$ & ND & ND & ND \\
\hline $20: 3 n-6$ & $1.48^{\mathrm{a}} \pm 0.23$ & $1.82^{\mathrm{a}} \pm 0.04$ & $0.82^{b} \pm 0.16$ & ND & ND & ND \\
\hline $20: 4 n-6$ & $2.18^{\mathrm{a}} \pm 0.28$ & $1.70^{\mathrm{b}} \pm 0.11$ & $1.37^{\mathrm{b}} \pm 0.11$ & ND & ND & ND \\
\hline $20: 5 n-3$ & $0.40^{\mathrm{a}} \pm 0.14$ & $0.36^{\mathrm{a}} \pm 0.27$ & $0.30^{\mathrm{a}} \pm 0.06$ & ND & ND & ND \\
\hline $21: 0$ & $2.43^{\mathrm{a}} \pm 0.35$ & $1.07^{\mathrm{b}} \pm 0.52$ & $0.68^{\mathrm{b}} \pm 0.12$ & ND & ND & ND \\
\hline $22: 6 n-3$ & $0.60^{\mathrm{a}} \pm 0.10$ & $0.62^{\mathrm{a}} \pm 0.04$ & $0.38^{\mathrm{a}} \pm 0.12$ & ND & ND & ND \\
\hline 24:0 & $0.63^{\mathrm{a}} \pm 0.16$ & $0.24^{\mathrm{b}} \pm 0.04$ & $0.26^{\mathrm{b}} \pm 0.06$ & ND & ND & ND \\
\hline $24: 1 n-9$ & $0.35^{\mathrm{a}} \pm 0.04$ & $0.30^{\mathrm{a}} \pm 0.03$ & $0.27^{\mathrm{a}} \pm 0.09$ & ND & ND & ND \\
\hline$\Sigma$ SFA & $152.47^{\mathrm{bA}} \pm 1.08$ & $194.01^{\mathrm{aA}} \pm 0.04$ & $104.80^{\mathrm{cA}} \pm 5.43$ & $10.43^{\mathrm{aB}} \pm 0.43$ & $12.13^{\mathrm{a} B} \pm 0.42$ & $12.85^{\mathrm{aB}} \pm 0.72$ \\
\hline$\Sigma$ MUFA & $126.39^{\mathrm{aA}} \pm 0.90$ & $102.33^{\mathrm{bA}} \pm 7.77$ & $91.72^{\mathrm{cA}} \pm 6.57$ & $7.07^{\mathrm{aB}} \pm 0.14$ & $6.05^{\mathrm{aB}} \pm 0.56$ & $7.09^{\mathrm{aB}} \pm 0.25$ \\
\hline$\Sigma$ PUFA & $16.51^{\mathrm{bA}} \pm 0.69$ & $47.23^{\mathrm{a}_{\mathrm{A}}} \pm 0.70$ & $37.65^{\mathrm{a}_{\mathrm{A}}} \pm 0.70$ & $3.24^{\mathrm{aB}} \pm 0.11$ & $2.93^{\mathrm{aB}} \pm 0.50$ & $2.34^{\mathrm{aB}} \pm 0.20$ \\
\hline$\Sigma \mathrm{n}-6$ & $18.49^{\mathrm{bA}} \pm 0.59$ & $44.56^{\mathrm{a}_{\mathrm{A}}} \pm 1.28$ & $36.11^{\mathrm{a}_{\mathrm{A}}} \pm 0.94$ & $3.24^{\mathrm{aB}} \pm 0.11$ & $2.93^{\mathrm{aB}} \pm 0.50$ & $2.34^{\mathrm{aB}} \pm 0.20$ \\
\hline$\Sigma \mathrm{n}-3$ & $1.76^{\mathrm{b}} \pm 0.13$ & $6.56^{\mathrm{a}} \pm 0.24$ & $4.07^{\mathrm{a}} \pm 0.74$ & - & - & - \\
\hline$\Sigma n-6 / n-3$ & $10.49^{\mathrm{a}} \pm 0.64$ & $6.79^{\mathrm{a}} \pm 0.83$ & $8.95^{\mathrm{a}} \pm 0.77$ & - & - & - \\
\hline Total & $295.37^{\mathrm{bA}} \pm 1.25$ & $343.57^{\mathrm{a}_{\mathrm{A}}} \pm 4.18$ & $234.17^{\mathrm{bA}} \pm 19.34$ & $20.74^{\mathrm{aB}} \pm 0.70$ & $21.11^{\mathrm{aB}} \pm 1.30$ & $22.28^{\mathrm{aB}} \pm 0.66$ \\
\hline
\end{tabular}

Results expressed as mean \pm SD (standard deviation) of three replicates. Equivalent phases of human milk were compared between the different methods. Means followed by different lowercase letters ( $\mathrm{a}$ and $\mathrm{b}$ ) on the same line are significantly different by the Tukey's test $(p<0.05)$. Different phases in the same method were also compared. Means followed by different uppercase letters (A and B) on the same line are significantly different by the Tukey's test ( $p<0.05$ ). ND: not detected; C: colostrum; T: transitional; M: mature; SFA: saturated fatty acid; MUFA: monounsaturated fatty acids; PUFA: polyunsaturated fatty acids.

analyze complex situations and establish alternatives decision. ${ }^{4,28}$ LCPUFAs were not identified in this study by the creamatocrit method.

Prior to the introduction of modern agriculture, the ratio of n-6 to n-3 fatty acids in the human diet was almost equivalent. However, due to changes in eating habits, this relationship in the western diet is currently superior than 10:1 and it is, at least in part, related to the development of cardiovascular diseases increase, among others. Therefore, nutrition societies recommend that the n-6 to $\mathrm{n}-3$ ratio must be up to $10: 1 .{ }^{29-31}$ FAs identified by the Folch method presented values demonstrating an ideal ratio (less than or equal to 10) of the $n-6$ to $n-3$ ratio in all HM pools.

\section{Principal component analysis (PCA)}

The PCA was performed to clarify the visualization of the contribution to the results obtained by GC-FID for each FA, using different methods to extract lipids from the HM pools. PC1 (95.11\%) and PC2 (3.6\%) explained $98.71 \%$ of the total variance (Figure 1). A separation in five different 
groups is observed. In the negative quadrant of PC1 and positive quadrant of $\mathrm{PC} 2$, one group was formed by the Folch lipid extraction method in the colostrum pool (FC) and FA 10 (18:1n-9), due to the high level of OA found. A second group formed by the Folch lipid extraction method in the transitional milk pool (FT) was grouped with FA 5 (16:0), which presented high PA concentrations.

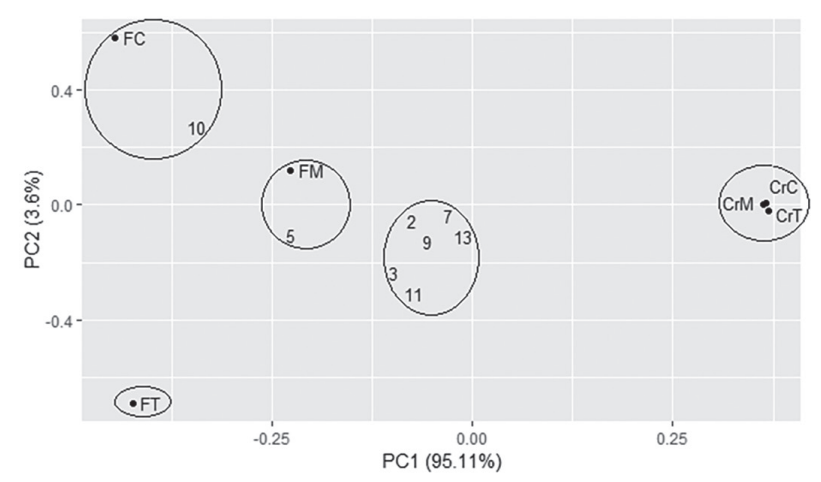

Figure 1. PCA of GC-FID data of the HM pool FAs $(2: 12: 0 ; 3: 14: 0$; 5: 16:0; 7: 17:0; 9: 18:0; 10: 18:1n-9; 11: 18:2n-6; 13: 18:3n-3); lipid extraction by Folch method in the colostrum pool (FC); transitional pool (FT); mature pool (FM) and by creamatocrit method in colostrum pool (CrC); transitional pool (CrT); mature pool (CrM).

All FAs by Folch method demonstrated results lower in the mature milk samples (FM) in comparison to the other pools, data from this method were separated from the other samples, forming a third group that contributed negatively to $\mathrm{PC} 1$ and $\mathrm{PC} 2$.

FAs 2 (12:0), 3 (14:0), 7 (17:0), 9 (18:0), 11 (18:2n-6) and 13 (18:3n-3) were grouped into a fourth group, due to the high FA values encoutered. The creamatocrit lipid extraction method in the different phases of $\mathrm{HM}$ pools (colostrum $(\mathrm{CrC})$; transitional $(\mathrm{CrT})$; mature $(\mathrm{CrM})$ ) contributed positively to $\mathrm{PC} 1$ and led to the formation of a fifth group, separated from all other FAs, since the results on the FA composition by this method were lower in comparison to those obtained by the Folch method.

\section{DI-ESI(+)-MS}

Although some researches have studied FA compositions in different lactation phases of HM, there is little research in the literature on the lipid and TAGs composition. The lipids identification by different methods was performed, using a computational simulation of the probable TAG composition present in different oil samples, developed by Antoniasi Filho et al..$^{32}$ Data are presented in Table 3, being the most intense ion peak in the spectrum assigned as $100 \%$ and the other peaks assigned with decreasing relative intensity in relation to the most intense peak. ${ }^{33}$
The peaks found in the 500 to $1000 \mathrm{~m} / \mathrm{z}$ region are presented in the colostrum pool spectra by the creamatocrit method (Figure 2), in the transitional pool (Figure 3) and in the mature HM pool (Figure 4). By the Folch method, colostrum, transitional and mature pools spectra are presented in the Figures 5, 6 and 7, respectively. Applying Folch methodology, the number of peaks was higher in all pools compared to the creamatocrit method, confirming the greater efficiency of lipid extraction; consequently, a greater number of possible TAGs and lipids were discovered using DI-ESI-MS.

Table 3 showed that the phospholipids distribution of lower molecular weight in relation to TAGs ( $>44$ carbons) was found in almost all samples of the colostrum pool using both methods, indicating that these changes in the HM lipid composition are part of a dynamic process, aiming to encounter the necessities of the baby during its development and growth. The glycerophospholipid $(\mathrm{m} / \mathrm{z}, 496)$ found using the Folch method in the colostrum pool spectrum (FC) and glycerophosphocholine/phosphoglycol $(\mathrm{m} / \mathrm{z} 713)$ found in concentrations above $40 \%$ in the Folch method of transitional pool spectra (FT), are lipids found in lower proportion in the HM in comparison to TAGs. However, glycerophosphocholine is a source of choline, and can have specific effects on plasma cholesterol levels and on baby's brain development. ${ }^{34}$ Therefore, the mature HM pools probably presented lower levels of these lipids, according to both methods ( $\mathrm{CrM}$ and FM), since it is a membrane constituents of HM fat globules and present extreme metabolic importance for the neonate in the first weeks of life. ${ }^{35}$

In the TAGs ranging from $\mathrm{m} / \mathrm{z}, 823$ to 873 , the predominance of $\mathrm{P}$ was noted among the combinations of TAGs in all HM pools, with intensity superior than $90 \%$ in the $m / z$ of 849 in the colostrum pool by Folch method. These FAs combinations were not indiscriminate, it is strategically placed in the TAGs due to the high requirement of energy in growing babies, who essentially use this FA as a direct source of energy. ${ }^{36}$

According to Table 3, the major peak in the CrT, FC and FT samples was $m / z 875$. The TAGs in these samples may be composed of the following combination of FAs identified by GC-FID: PPoAa/PLLn/PoLL (Po: palmitoleic acid). In the $\mathrm{CrC}, \mathrm{CrM}$ and FM samples, the possible TAGs could be PoOL/PLL/PPoDGLA (DGLA: dihomo-gamma-linolenic acid), according to the most intense peak $(\mathrm{m} / \mathrm{z}$ 877). It was possible to observe that the FAs most abundant in the TAG combinations in all HM pools were palmitic and linoleic acids, which were also the predominant FAs (saturated and polyunsaturated, respectively) found by GC-FID. These FAs combinations in the TAGs detected by DI-ESI-MS 
Table 3. Lipid composition and relative intensity detected via DI-ESI(+)-MS of human milk pools spectra

\begin{tabular}{|c|c|c|c|c|c|c|c|c|}
\hline \multirow{2}{*}{$m / z$} & \multirow{2}{*}{ Composition } & \multirow{2}{*}{ Possible lipids } & \multicolumn{6}{|c|}{ Relative intensity $/ \%$} \\
\hline & & & $\mathrm{CrC}$ & $\mathrm{CrT}$ & $\mathrm{CrM}$ & $\mathrm{FC}$ & FT & FM \\
\hline 496 & $\mathrm{C}_{24} \mathrm{H}_{50} \mathrm{NO}_{7} \mathrm{P}$ & glycerophospholipid - 16:0 LysoPC & - & - & - & 6.03 & - & - \\
\hline 639 & $\mathrm{C}_{39} \mathrm{H}_{68} \mathrm{O}_{5}$ & DG 18:2/18:2 & - & - & - & - & - & 2.6 \\
\hline 713 & $\mathrm{PC}(32: 0)+\mathrm{K}$ & glycerophosphocholine/phosphoglycerol & - & 43.58 & 5.80 & 29.47 & 48.54 & 17.42 \\
\hline 739 & $\mathrm{C}_{38} \mathrm{H}_{75} \mathrm{O}_{11} \mathrm{P}$ & PG $(32: 0(\mathrm{OH}))$ & 16.85 & 58.92 & 12.03 & 37.63 & 61.09 & - \\
\hline 793 & $\begin{array}{c}\mathrm{C}_{42} \mathrm{H}_{75} \mathrm{O}_{10} \mathrm{P} / \\
\mathrm{C}_{44} \mathrm{H}_{82} \mathrm{O}_{10}\end{array}$ & PG (36:4) & 30.14 & 80.09 & - & 67.48 & 82.91 & 61.36 \\
\hline 795 & $\mathrm{C}_{42} \mathrm{H}_{77} \mathrm{O}_{10} \mathrm{P}$ & PG (36:3) & 42.3 & 84.51 & 51.79 & 79.25 & 85.05 & 74.46 \\
\hline 819 & $\mathrm{C}_{44} \mathrm{H}_{77} \mathrm{O}_{10} \mathrm{P}$ & PG (38:5) & 24.90 & 74.02 & 20.01 & 63.32 & 79.66 & - \\
\hline 821 & $\mathrm{C}_{44} \mathrm{H}_{79} \mathrm{O}_{10} \mathrm{P}$ & PG (38:4) & 49.93 & 89.46 & 33.43 & 79.85 & 89.83 & - \\
\hline 823 & $\mathrm{C}_{51} \mathrm{H}_{92} \mathrm{O}_{6}$ & PoPoPo & - & 69.99 & - & - & 72.04 & 70.38 \\
\hline 824 & $\mathrm{C}_{51} \mathrm{H}_{98} \mathrm{O}_{6}$ & PPP/MPS & - & - & - & 54.09 & - & 43.62 \\
\hline 825 & $\mathrm{C}_{51} \mathrm{H}_{94} \mathrm{O}_{6}$ & PPoPo & - & 26.31 & - & - & 22.06 & 23.51 \\
\hline 847 & $\mathrm{C}_{53} \mathrm{H}_{92} \mathrm{O}_{6}$ & PoPoLn & 57.94 & 81.04 & 48.28 & 74.14 & 80.32 & 58.63 \\
\hline 849 & $\mathrm{C}_{53} \mathrm{H}_{94} \mathrm{O}_{6}$ & PPoLn/MLL & 77.44 & 88.01 & 62.23 & 90.83 & 86.70 & 82.98 \\
\hline 850 & $\mathrm{C}_{53} \mathrm{H}_{100} \mathrm{O}_{6}$ & OPP/PPoS & - & 63.25 & - & - & 66.14 & - \\
\hline 851 & $\mathrm{C}_{53} \mathrm{H}_{96} \mathrm{O}_{6}$ & PPLn/PPoL/PoPoO & - & - & - & 76.56 & - & 76.24 \\
\hline 873 & $\mathrm{C}_{55} \mathrm{H}_{94} \mathrm{O}_{6}$ & PPoEpa & - & 90.51 & - & 89.15 & 80.66 & - \\
\hline 875 & $\mathrm{C}_{55} \mathrm{H}_{96} \mathrm{O}_{6}$ & PPoAa/PLLn/PoLL & 93.12 & 100.00 & 92.64 & 100.00 & 100.00 & 96.20 \\
\hline 877 & $\mathrm{C}_{55} \mathrm{H}_{98} \mathrm{O}_{6}$ & PoOL/PLL/PPoDGLA & 100.00 & 97.89 & 100.00 & 98.09 & 98.09 & 100.00 \\
\hline 878 & $\mathrm{C}_{55} \mathrm{H}_{104} \mathrm{O}_{6}$ & SPoS/AOM/APoP/SOP & 86.76 & - & 85.81 & 96.07 & - & 92.96 \\
\hline 879 & $\mathrm{C}_{55} \mathrm{H}_{100} \mathrm{O}_{6}$ & POL & - & 49.06 & 78.75 & 81.22 & 49.15 & 89.48 \\
\hline 880 & $\mathrm{C}_{55} \mathrm{H}_{106} \mathrm{O}_{6}$ & SSP & - & - & - & 55.63 & - & - \\
\hline 899 & $\mathrm{C}_{57} \mathrm{H}_{96} \mathrm{O}_{6}$ & OLnLn/LLLn & - & 69.29 & 43.93 & 72.13 & 65.58 & 29.28 \\
\hline 901 & $\mathrm{C}_{57} \mathrm{H}_{98} \mathrm{O}_{6}$ & OLLn/LLL & 75.34 & 74.23 & 73.38 & 94.20 & 76.69 & - \\
\hline 903 & $\mathrm{C}_{57} \mathrm{H}_{100} \mathrm{O}_{6}$ & OOLn & 68.64 & 62.40 & - & 85.63 & 57.08 & 66.19 \\
\hline 925 & $\mathrm{C}_{59} \mathrm{H}_{98} \mathrm{O}_{6}$ & PLDha/OLEpa/LLAa & - & 2.450 & - & - & 2.24 & - \\
\hline 927 & $\mathrm{C}_{59} \mathrm{H}_{100} \mathrm{O}_{6}$ & SSO/PODha/OOEpa/OLAa/PDGLAAa/OLnDGLA & - & - & - & - & - & - \\
\hline 929 & $\mathrm{C}_{59} \mathrm{H}_{102} \mathrm{O}_{6}$ & PLAa/SLAa/OOAa/OLDGLA & - & - & - & - & - & - \\
\hline
\end{tabular}

aResults expressed as mean of three spectral replicates. CrC: creamatocrit method and colostrum pool spectra; CrT: creamatocrit method and transitional pool spectra; CrM: creamatocrit method and mature pool spectra; FC: Folch method and colostrum pool spectra; FT: Folch method and transitional pool spectra; FM: Folch method and mature pool spectra; PG: phosphoglicerol; Po: palmitoleic acid; P: palmitic acid; M: myristic acid; S: stearic acid; Ln: linolenic acid; L: linoleic acid; O: oleic acid; Epa: eicosapentaenoic acid; Aa: arachidonic acid; DGLA: dihomo-gamma-linolenic acid; A: arachidic acid; Dha: docosahexaenoic acid.

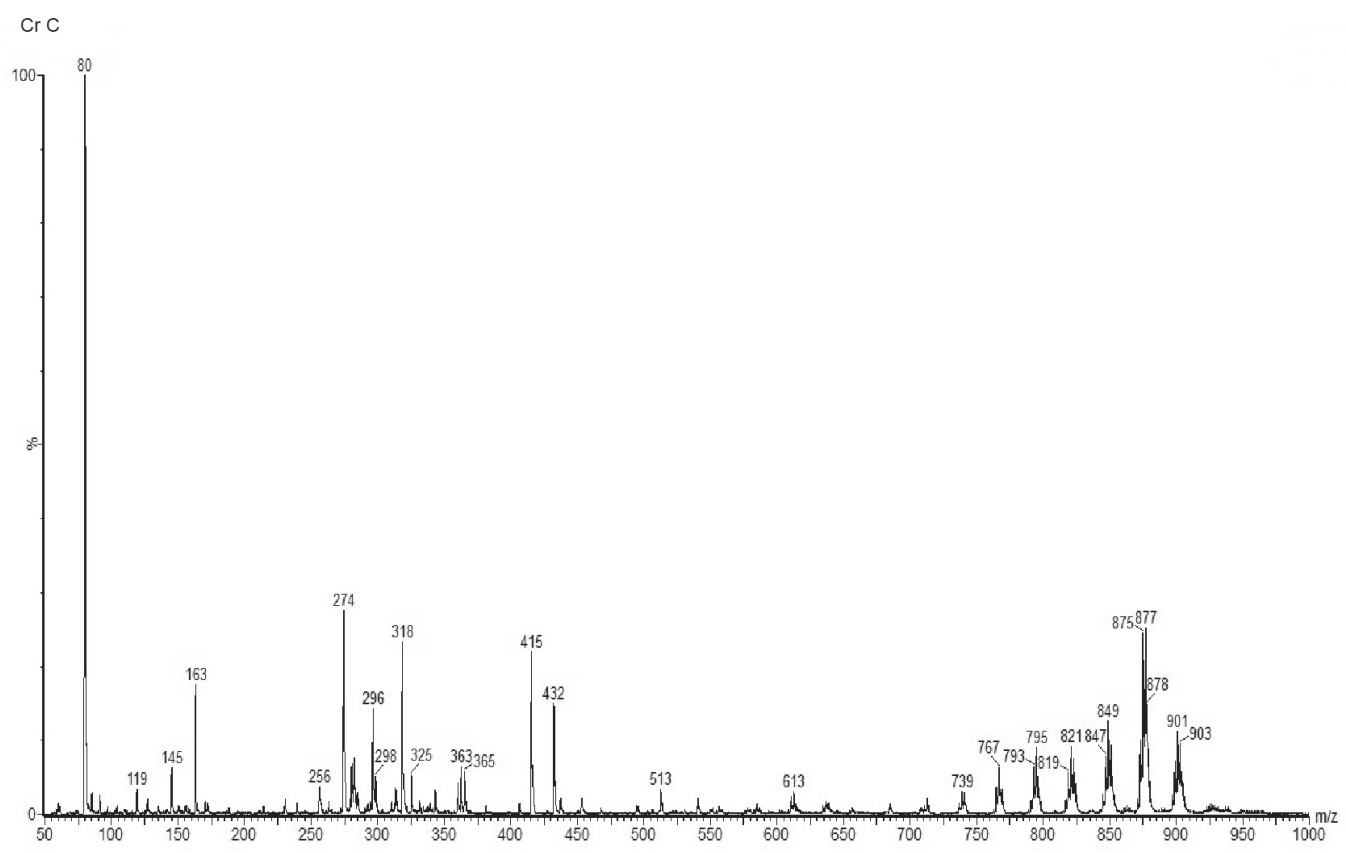

Figure 2. Creamatocrit method of colostrum pool spectra, from DI-ESI(+)-MS. 


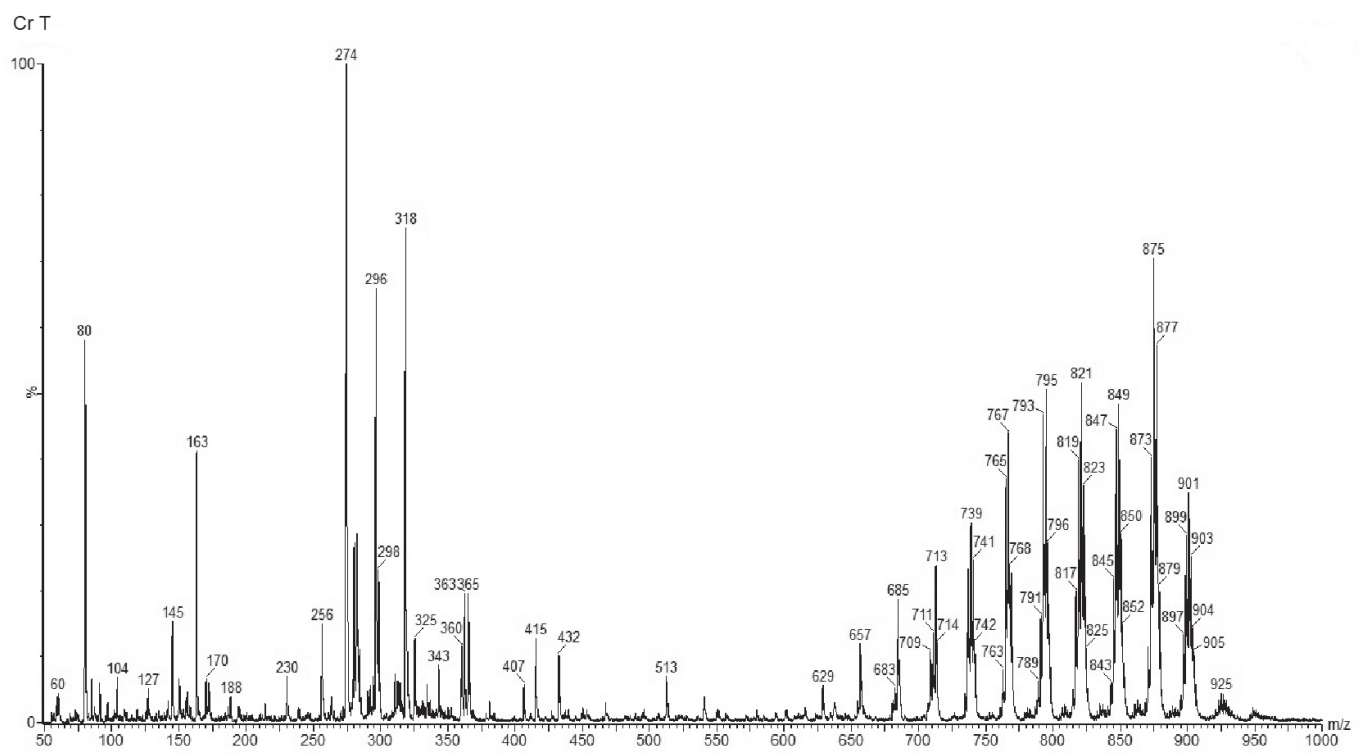

Figure 3. Creamatocrit method of transitional pool spectra, from DI-ESI(+)-MS.

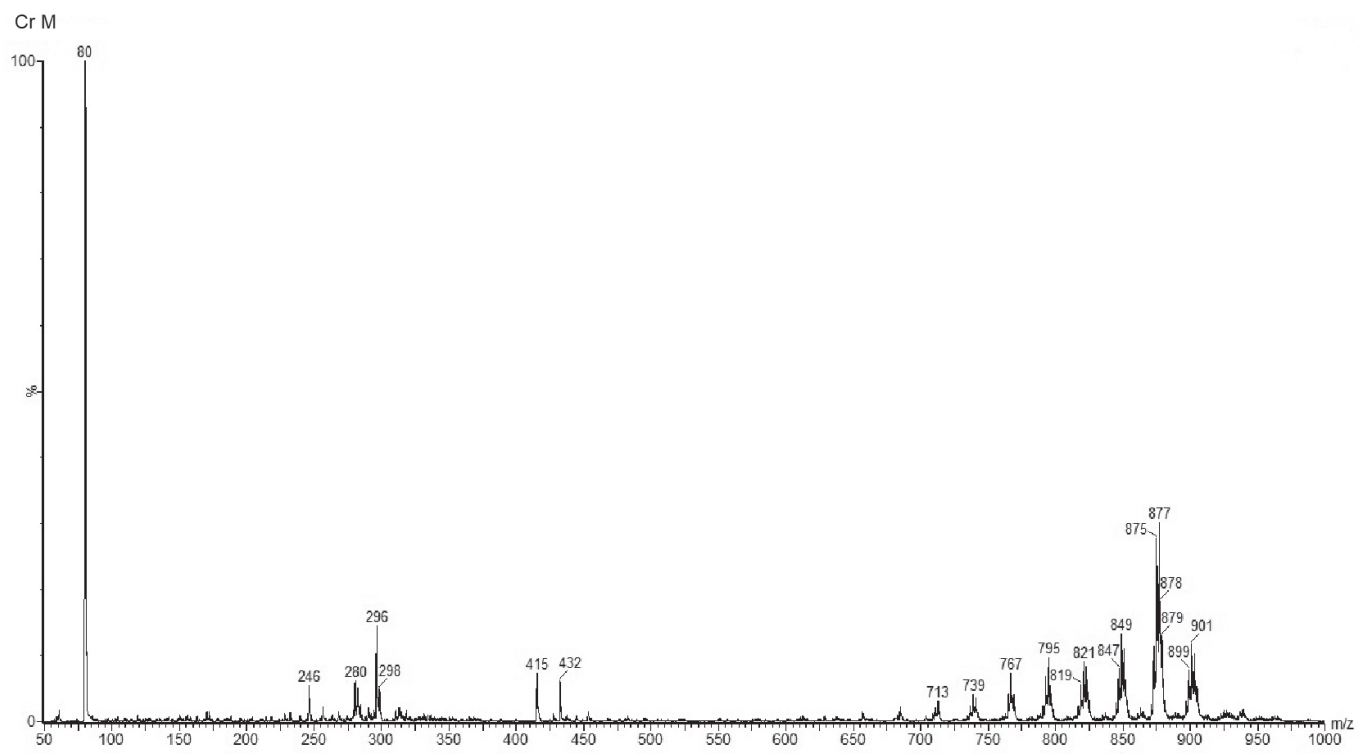

Figure 4. Creamatocrit method of mature pool spectra, from DI-ESI(+)-MS.

are in accordance with the literature, and it represents more than half of all FAs in the samples evaluated in the present study. The results obtained agreed with a study by Kallio et al. ${ }^{37}$ in which they evaluated TAGs in pooled Chinese and Finnish HM samples, it was concluded that these FAs may be influenced by factors such as local eating habits, but remain the predominant FAs.

The results display that TAGs with $\mathrm{m} / \mathrm{z}$ above 878 present a greater predominance of linoleic acid. However, combinations of TAGs composed of palmitic acid are rarely found in this $\mathrm{m} / \mathrm{z}$ region. In a study by Tu et al., ${ }^{36}$ in which TAGs in HM pools collected at different phases of lactation and in infant formulas were also evaluated by DI-ESI-MS, it was discovered that PUFAs predominated in the higher molecular weight composite TAGs. This result can be justified by the pronounced requirement for these FAs, since it is precursor of LCPUFAs with different functions, ${ }^{4,28}$ as already discussed in the present work.

\section{Conclusions}

Creamatocrit method is a lipid extraction methodology applied in human milk banks even though Folch method is considered reference for lipid extraction. Hence, this study compared the FA composition by GC-FID and the lipid profile by DI-ESI-MS in different phases of HM pools. 


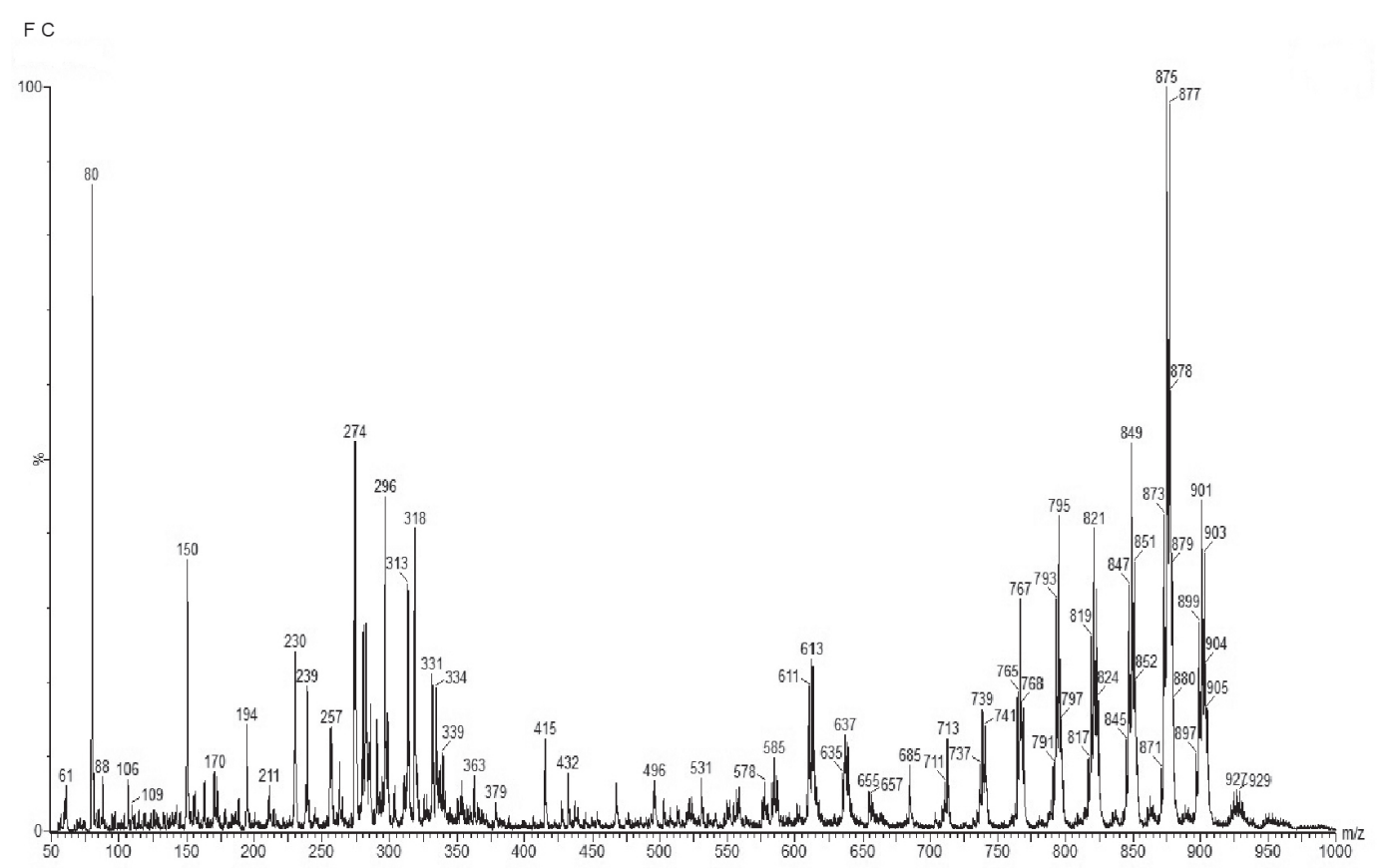

Figure 5. Folch method of colostrum pool spectra, from DI-ESI(+)-MS.

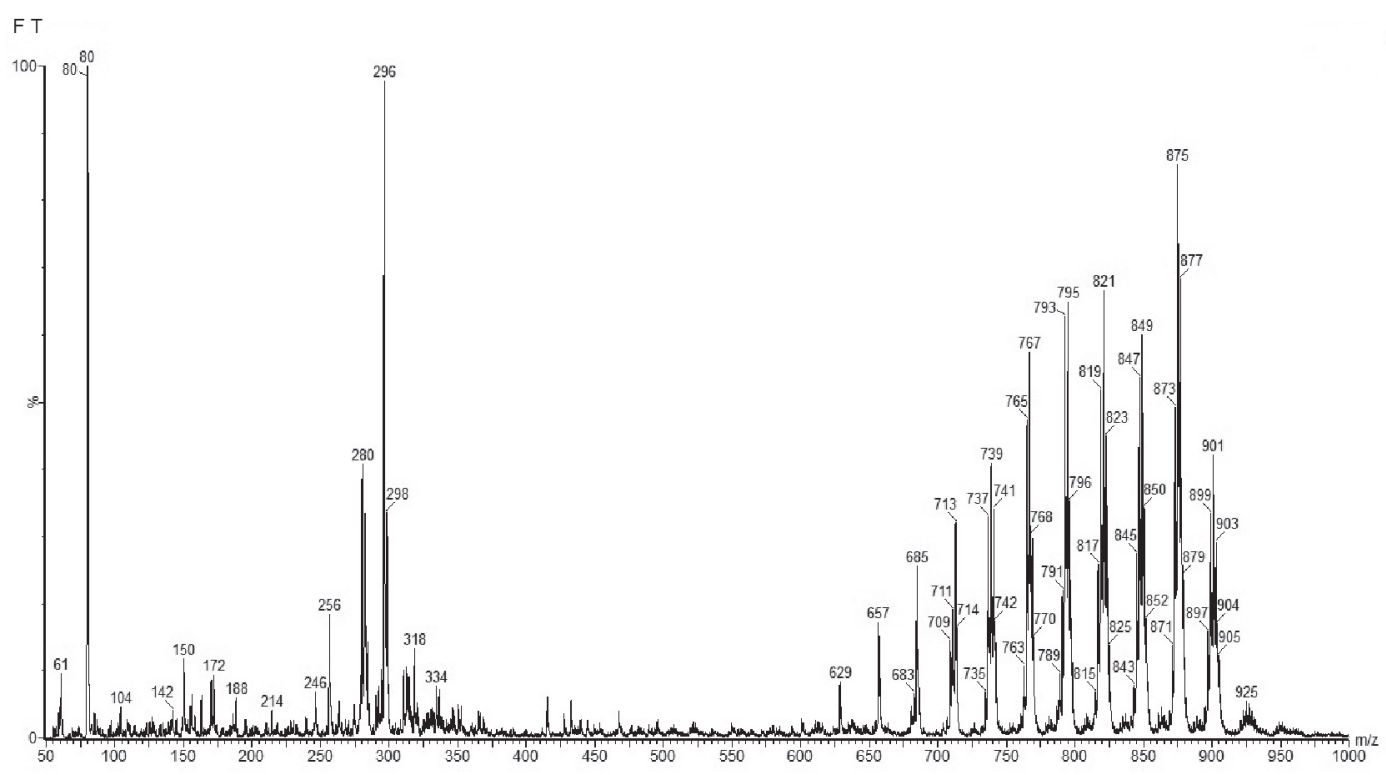

Figure 6. Folch method of transitional pool spectra, from DI-ESI(+)-MS.

Lipid extraction from HM pools by the Folch method were more effective than the creamatocrit method, which can be verified by the higher number of FAs determined by GC-FID and also by the greater number and intensity of peaks found in the DI-ESI-MS spectra in all HM pools. The lipid profile of the HM samples by the creamatocrit method revealed that this method is able to extract lipids with less effectiveness in comparison to the reference method. The samples from the transitional HM pool presented the highest lipid levels, which was confirmed by DI-ESI-MS. FA analysis by GC-FID in combination with PCA proved to be a powerful tool to elucidate which samples were highlighted regarding the FA content, as well as that Folch method was the most suited to determine the lipid content of each sample. Therefore, Folch method can replace the creamatocrit method in HMB to determine the HM lipid content.

\section{Acknowledgments}

The authors would like to thank CAPES, Fundação Araucária and CNPq for their financial support and 


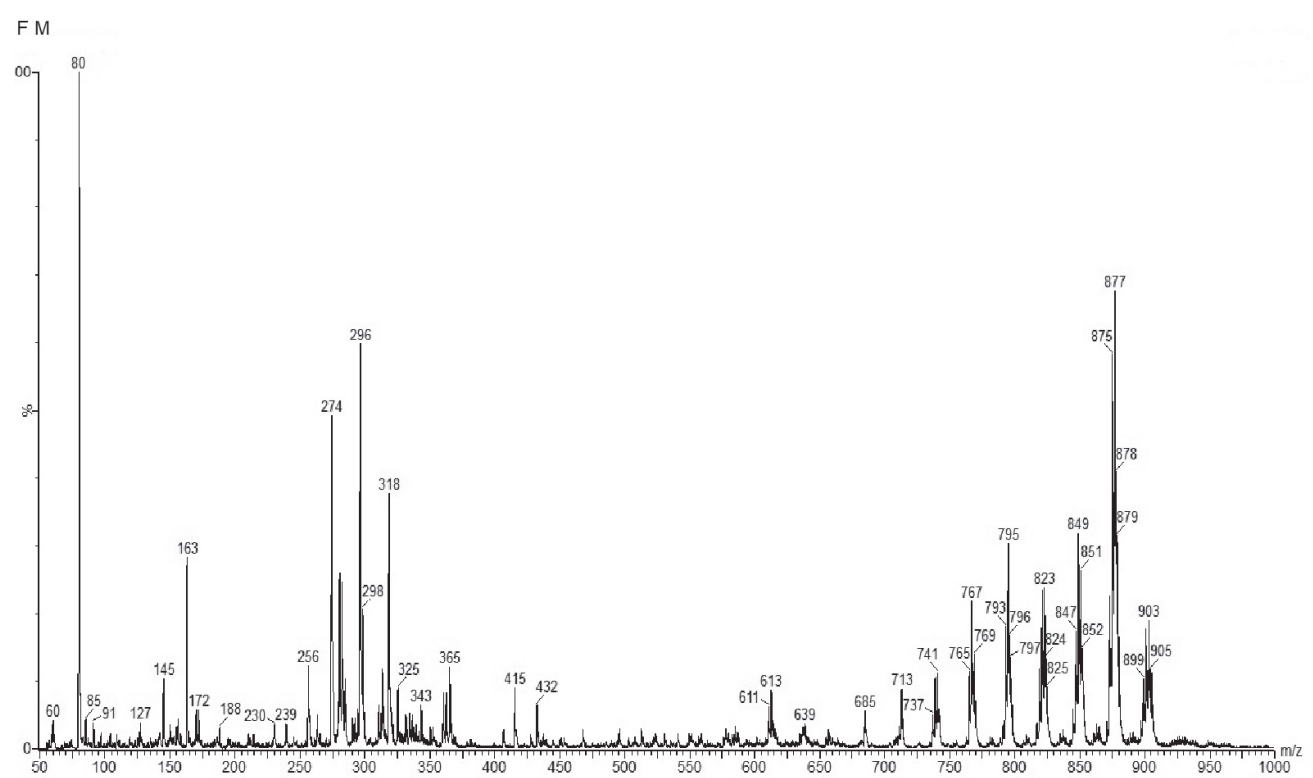

Figure 7. Folch method of mature pool spectra, from DI-ESI(+)-MS.

fellowships, as well as HMB for the partnership and the donation of HM samples.

\section{References}

1. Victora, C. G.; Bahl, R.; Barros, A. J. D.; França, G. V. A.; Horton, S.; Krasevec, J.; Murch, S.; Sankar, M. J.; Walker, N.; Rollins, N. C.; Lancet 2016, 387, 475.

2. Kumar, A.; Lindley, M. R.; Mastana, S. S.; Godswill, N.-N.; Frank, N.-E. G.; Edson, M.-Y. J.; Emmanuel, Y.; Martin, B. J.; Hermine, N.-B.; Kingsley, T.-M.; Constant, L.-L.-N. B.; Armand, N.-M.; Res. Plant Sci. 2014, 5, 760.

3. Ballard, O.; Morrow, A. L.; Pediatr. Clin. North Am. 2013, 60, 49.

4. Koletzko, B.; Ann. Nutr. Metab. 2016, 69, 28.

5. Abrahamse, E.; Minekus, M.; van Aken, G. A.; van de Heijning, B.; Knol, J.; Bartke, N.; Oozeer, R.; van der Beek, E. M.; Ludwig, T.; Food Dig. 2012, 3, 63.

6. Gallier, S.; Vocking, K.; Post, J. A.; van de Heijning, B.; Acton, D.; van der Beek, E. M.; van Baalen, T.; Colloids Surf., B 2015, $136,329$.

7. Demmelmair, H.; Koletzko, B.; Best Pract. Res., Clin. Endocrinol. Metab. 2018, 32, 57.

8. Mehrotra, V.; Sehgal, S. K.; Bangale, N. R.; Clin. Epidemiol. Glob. Heal. 2018, in press, DOI 10.1016/j.cegh.2018.03.005.

9. Iranpour, R.; Kelishadi, R.; Babaie, S.; Khosravi-Darani, K.; Farajian, S.; J. Res. Med. Sci. 2013, 18, 1.

10. Du, J.; Gay, M. C. L.; Lai, C. T.; Trengove, R. D.; Hartmann, P. E.; Geddes, D. T.; Food Chem. 2017, 217, 505.

11. Folch, J.; Lees, M.; Sloane-Stanley, G. H.; J. Biol. Chem. 1957, 226, 497.

12. Lucas, A.; Gibbs, J. A. H.; Lyster, R. L. J.; Baum, J. D.; BMJ [Br. Med. J.] 1978, 1, 1018.
13. Meier, P. P.; Engstrom, J. L.; Murtaugh, M. A.; Vasan, U.; Meier, W. A.; Schanler, R. J.; J. Perinatol. 2002, 22, 646.

14. Yan, Y.; Wang, Z.; Wang, X.; Wang, Y.; Xiang, J.; Kothapalli, K. S. D.; Brenna, J. T.; J. Funct. Foods 2017, 29, 172.

15. Baiocchi, C.; Medana, C.; Dal Bello, F.; Giancotti, V.; Aigotti, R.; Gastaldi, D.; Food Chem. 2015, 166, 551.

16. Hartman, L.; Lago, R. C.; Lab. Pract. 1973, 22, 475.

17. Simionato, J. I.; Garcia, J. C.; dos Santos, G. T.; Oliveira, C. C.; Visentainer, J. V.; de Souza, N. E.; J. Braz. Chem. Soc. 2010, 21,520 .

18. Visentainer, J. V.; Quim. Nova 2012, 35, 274.

19. Youzbachi, N.; Trabelsi, H.; Elfalleh, W.; Khaldi, A.; Nasri, N.; Tlili, N.; Arabian J. Chem. 2015, DOI: 10.1016/j. arabjc.2015.08.020.

20. RStudio Team; RStudio: Integrated Development for R; RStudio, Inc., Boston, MA, USA, 2015. Available at http:// www.rstudio.com/, accessed in December 2018.

21. O’Neill, E. F.; Radmacher, P. G.; Sparks, B.; Adamkin, D. H.; J. Pediatr. Gastroenterol. Nutr. 2013, 56, 569.

22. Carbonera, F.; Montanher, P. F.; Figueiredo, I. L.; Bonafé, E. G.; Santos Jr., O. O.; Sargi, S. C.; Gonçalves, R. M.; Matsushita, M.; Visentainer, J. V.; J. Am. Oil Chem. Soc. 2016, 93, 1255.

23. Petit, V.; Sandoz, L.; Garcia-Rodenas, C. L.; Prostaglandins, Leukotrienes Essent. Fatty Acids 2017, 121, 40.

24. Carta, G.; Murru, E.; Lisai, S.; Sirigu, A.; Piras, A.; Collu, M.; Batetta, B.; Gambelli, L.; Banni, S.; PLoS One 2015, 10, e0120424.

25. Moltó-Puigmartí, C.; Castellote, A. I.; Carbonell-Estrany, X.; López-Sabater, M. C.; Clin. Nutr. 2011, 30, 116.

26. Martínez, M.; Mougan, I.; J. Neurochem. 1998, 71, 2528.

27. Scopesi, F.; Ciangherotti, S.; Lantieri, P. B.; Risso, D.; Bertini, 
I.; Campone, F.; Pedrotti, A.; Bonacci, W.; Serra, G.; Clin. Nutr. 2001, 20, 393.

28. Brown, T. T.; Jernigan, T. L.; Neuropsychol. Rev. 2012, 22, 313.

29. Connor, W. E.; Am. J. Clin. Nutr. 2000, 71, 171S.

30. Simopoulos, A.; Biomed. Pharmacother. 2002, 56, 365.

31. Russo, G. L.; Biochem. Pharmacol. 2009, 77, 937.

32. Antoniasi Filho, N. R.; Mendes, O. L.; Lanças, F. M.; Chromatographia 1995, 40, 557.

33. Santos, L. S.; Catharino, R. R.; Aguiar, C. L.; Tsai, S. M.; Eberlin, M. N.; J. Radioanal. Nucl. Chem. 2006, 269, 505.
34. Lewis, E. D.; Field, C. J.; Jacobs, R. L.; Lipid Technol. 2015, 27, 227.

35. Jensen, R. G.; J. Dairy Sci. 2002, 85, 295.

36. Tu, A.; Ma, Q.; Bai, H.; Du, Z.; Food Chem. 2017, 221, 555.

37. Kallio, H.; Nylund, M.; Boström, P.; Yang, B.; Food Chem. $\mathbf{2 0 1 7}, 233,351$.

Submitted: November 30, 2018 Published online: January 11, 2019 